\title{
Elementos Narrativos que Sirven para Generar Convergencias e Inteligibilidad en Narrativas Transmediáticas o Narrativas Interactivas Lineales
}

\section{Narrative Elements that Serve to Generate Convergences and Inteligibilty in Transmedia Narratives or Interactive Linear Narratives}

\author{
Jorge Ignacio Mora-Fernández \\ Fundador y Co-director Grupo I+D+C CICNETART \\ (Programa Prometeo, SENESCYT, Universidad de Cuenca) \\ Researcher Affiliated Arthur C. Clarke Center for Human Imagination \\ (UCSD, University of California San Diego)
}

Fecha de recepción: 5 de diciembre de 2016

Fecha de revisión: 18 de diciembre de 2016

Para citar este artículo: Mora-Fernández, J. I. (2017): Elementos Narrativos que Sirven para Generar Convergencias e Inteligibilidad en Narrativas Transmediáticas o Narrativas Interactivas Lineales, Icono 14, volumen 15 (1), pp. 186-210. doi: 10.7195/ri14.v15i1.1032 


\section{Resumen}

El término transmedia fue acuñado por Marsha Kinder (1991) para referirse a la intertextualidad entre películas, series de televisión de dibujos y los juguetes para niños y jóvenes preadolescentes. En dicha publicación participaba Henry Jenkins, quien posteriormente profundizó en el término de transmedia en Media Convergence (2006). La presente investigación analiza el uso de los elementos narrativos y de las características de los medios de comunicación utilizados para generar narrativas transmedia para poder utilizarlas en productos comunicativos independientes. Este artículo se concentra en el análisis transmedia del universo narrativo generado por los cómics, películas, web, videos de fans y videojuegos de Batman. El objetivo es el estudio de los elementos narrativos de las acciones, personajes, espacios y tiempos utilizados para generar convergencia e inteligibilidad comunicativas transmedia que retroalimentan coherentemente el universo de Batman, sus narrativas interactivas lineales y circulares. De esta forma es posible aplicar dichas técnicas narrativas transmedia a la construcción de productos comunicativos independientes y de edutainment.

Palabras clave: Narrativa hipermedia y transmedia - Comunicación - Cine interactivos - Cultura digital - Lúdico-educativo

\section{Abstract}

The term transmedia was initially used by Marsha Kinder (1991:40) to refer to the intertextuality between Films, animation TV series and toys for children and young children. On that publication, Henry Jenkins participated with a chapter, who later on develop farther the term transmedia on Media Convergence (2006). The present research analyzes the application of narrative elements and media characteristics used to generate transmedia narratives so they can be used to generate on independent communications products. This article focuses on the transmedia analysis of the narrative universe generated by the comic, films, webs, fans video, and videogames of Batman. The goal is the study the narrative elements of the actions, characters, spaces and times used to generate transmedia communicative convergence and intelligibility that creates coherent feedback into the Batman universe, their linear and circular interactive narratives. In this way is possible to apply these transmedia narrative techniques to the construction of independent and edutainment communication products.

Key Words: Hypermedia and transmedia narratives - Interactive Cinema - Communications - Digital Culture - Edutainment 


\section{Introducción}

La presente investigación analiza el uso de narrativas transmedia enfocadas en un caso de éxito mediático que es el universo de Batman, uno de los más humanos de los denominados superhéroes. La motivación es estudiar cómo los elementos narrativos de acciones, personajes, espacios y tiempos han sido desarrollados en el fenómeno transmedia de las historias de Batman: cómics, películas, videojuegos, etc, para posteriormente aplicar dichos elementos narrativos transmedia al diseño y la creación de productos independientes y de edutainment, lúdico educativos.

\subsection{Conceptos de Convergencia, Narrativa Transmedia e Inteligibilidad Narrativas}

El concepto de transmedia fue inicialmente utilizado por Marsha Kinder (1991:40) para referirse a la intertextualidad transmediática. Henry Jenkins (2011) es quien popularizó el término narrativa transmedia, transmedia storytelling, como:

"La narrativa transmedia representa un proceso donde elementos integrales de una ficción se consiguen dispersar sistemáticamente a través de múltiples canales de distribución con el propósito de crear una experiencia unificada y coordinada. Idealmente, cada media hace su propia y única contribución al desarrollo de la historia" (Jenkins, 2011, p. de blog http://henryjenkins.org/).

En esta investigación también se utiliza el concepto de covergencia como un paradigma para pensar en el momento actual del cambio mediático, que está definido por la estratificación, diversificación e interconexión de los medios (Jenkins, 2006).

El mismo autor recopilaba diversas aplicaciones de dicha convergencia, por ejemplo en el caso de la retroalimentación entre la serie televisiva Lost y las interacciones con su desarrollo mediante blogs. Debido a las prácticas comunicativas actuales, Jenkins continúa señalando como la terminología utilizada como convergencia va evolucionando hacia el término transmedia, (Jenkins, 2011), (Scolari, 2013). 


\section{MONOGRÁFICO}

En este sentido la narrativa transmedia genera un universo narrativo de posibilidades lineales y/o circulares, donde las historias comienzan y acaban retroalimentándose y experimentadas una de cada vez en el tiempo. En ese sentido investigaciones recientes que siguen la línea de Jenkins expresan como la linealidad de la interactividad en este sentido es entendida como el flujo coherente comunicativo inmersivo en multiniveles: estético, narrativo y emocional (Mora, 2013).

\subsection{Conceptos de Inmersión, Tipos de interacción y Agencia}

Las narrativas transmedia por su propia naturaleza son interactivas ya que requieren de la participación del espectador en ir recopilando información de los diversos medios donde la narrativa se difunde. En ese sentido se genera inmersión dado que el contenido narrativo debe ser lo suficiente atractivo para el espectador como para convertirse en lectoautor, (Moreno, 2002), al buscar explorar el espacio narrativo de los contenidos diseminados en los diversos media. Igualmente se debe generar agencia dado que el lectoautor debe sentir la posibilidad de seguir ampliando su intriga o curiosidad de complementar la información narrativa de la historia convirtiéndose en un narrador. La inmersión es el sentimiento de estar presente en otro lugar y comprometido con la acción que allí ocurre (Mateas \& Murray, 2004, p.2-33). Mora aplica este concepto al contexto del diseño y análisis de los diversos tipos de interacción (2009, p.191).

\subsection{Conceptos relacionados con la "Paradoja Narrativa": DAA, Inteligibilidad Narrativa y Cierre Narrativo}

Los anteriores y los conceptos que se describen a continuación son conceptos narrativos que deben ser tenidos en cuenta a la hora de integrar los elementos narrativos en una historia transmedia. De esta forma se puede estudiar cómo se producen estos fenómenos narrativos, para obtener la inmersión comunicativa transmediática, mediante la combinación de los elementos narrativos de espacios, tiempos, acciones y personajes y los tipos de interacción que permite el acceso a los diversos media en los que se difunde. Todos estos conceptos descritos son incluidos para poder observar como la "paradoja narrativa" es resuelta mediante el diseño de una narrativa transmedia. La "paradoja narrativa" es descrita como "la 
relación entre la autoría y la interactividad que es percibida inversamente proporcional". (Bruni, 2013, p.18).

En dicho sentido la naturaleza enciclopédica, la producción de diversas series de cómics, televisión y cine realizadas por diversos autores del universo generado alrededor del personaje de Batman cuenta con dicha paradoja narrativa. Al tener varios autores ofrece amplias posibilidades a la audiencia de acceder a dichos contenidos y experimentar los diversos mundos del universo narrativo Batman desde diversas perspectivas y con un orden estructural. De esta forma, es la audiencia en último término, y las interacciones de intercambio de información entre ellos, lo que permite reorganizar la narrativa transmedia y personalizar su propia experiencia.

Hay algunos otros conceptos que son necesarios de describir y de observar para comprender cómo los proyectos intentan resolver la "paradoja narrativa", uno de ellos es la Distancia Autor Audiencia. El DAA depende de cuán efectivo es el compartir del código y el sistema utilizados entre el autor y la audiencia (Bruni, 2013, p.13-15).

En el transmedia la DAA se consigue gracias a que el autor tiene en cuenta, en su estrategia narrativa transmedia, acercarse al universo narrativo previamente creado y más conocido por sus fans, así como los comentarios e inputs de los mismos en sus webs y creaciones. Así la obra que genera estará llena de elementos narrativos reconocibles y al tiempo originales que aporten nuevos significados a los ya existentes. Otro importante concepto relacionado con la "paradoja narrativa" y la DAA es la inteligibilidad narrativa, (Bruni and Baceviciute, 2013, p.22), donde la fidelidad de la transmisión, o cuan cercana la DAA es, depende del alineamiento entre el significado que procura el autor y aquel que es comprendido por la audiencia.

En este sentido a nivel de transmedia el manejar los elementos de las acciones narrativas y características de los personajes permite que autores y audiencia manejen los mismo códigos y reglas de las estructuras narrativas. Otro importante concepto es el cierre narrativo "...el proceso donde la audiencia puede construir su significado en base a lo que esta siendo mediado, independientemente de que el significado corresponda o se acerque al que el autor intenta..." (Bruni y Baceviciute, 2013). 


\section{MONOGRÁFICO}

El cierre narrativo donde la audiencia puede construir su significado, (Bruni y Baceviciute, 2013), es algo sugerido por Tyler Weaver (2012) que ocurra en la narrativa que se muestra en cada media, de esa forma la narrativa transmedia nutre y abre puertas, para que las "audiencias absorbentes" se satisfagan con cada experiencia de cada media y deseen invertir más tiempo en los mundos de otros media, que configuran el universo transmedia. Para incluir una clara comprensión y proveer de la dinámica interactiva entre autores y audiencias a la inteligibilidad y cierre narrativo, es también importante añadir el concepto de narrativas emergentes tomado de la definiciones de Jenkins (2006), y Truesdale et al (2013), y descritas en palabras de Hurup Bevensee y Schoenay-Fog (2013) como: “....material narrativo a través de un rico ambiente y personajes inteligentes, con los cuales el usuario es capaz de identificarse, interpretar, y en último término construir su propia comprensión de la historia".

\section{Material y Métodos}

\subsection{Objetivo de Investigación}

La presente investigación analiza cómo se genera la narrativa transmedia mediante el uso de los elementos narrativos y de las características de los medios de comunicación utilizados para generar narrativas transmedia de éxito popular para utilizarlas en productos comunicativos independientes y de edutainment, o lúdico educativos. El análisis se realiza mediante un modelo previamente experimentado y validado por Mora-Fernández $(2009,2012)$.

\subsection{Antecedentes del Objeto de Estudio y del Material Analizado}

Las obras transmediáticas analizadas son propuestas narrativas que sirven para comprender como pueden llegar a influir incluso en la realización de secuencias en películas como es el caso de The Dark Knigth donde el genial C. Nolan incluye a los fans y seguidores de Batman, en el caso de la película disfrazados y armados para ayudar a Batman en la tarea de limpiar Gotham City del crimen, intentando pelear junto a él contra el Espantapájaros; y con la desafortunada suerte de finalmente caer en manos del Joker, quien no les perdona sus vidas a no ser que Batman re- 
vele su verdadera identidad. Esta competencia entre los seguidores de Batman y el Joker, sirvió a Nolan para diseñar una campaña transmediática de colaboradores de unos u otro previo al estreno de la película, mediante la campaña interactiva www. whysoserious.com, generando así una continuidad en el diálogo entre Batman y Joker así como entre los fans seguidores de uno y otro. Estos son los denominados crosplayers, individuos que siguen la moda en la que los fans se disfrazan de héroes e interactúan incluso unos con otros, muchas veces en contextos de festivales, lanzamientos o eventos relacionados con el universo narrativo de sus héroes, para crear una subcultura de juegos de rol. Todas estas interacciones narrativas podrían, desde una perspectiva de conjunto, denominarse como linealidad interactiva, dado que se provee con mundos narrativos y espacios de acceso al universo de Batman interactivos, Comic-con, videojuegos, web, etc que se complementan linealmente con la coherencia temática e inteligibilidad que facilita el estreno de la película con una narrativa lineal más cerrada.

En esta investigación se tuvo que decidir un lugar de entrada más afín al perfil y experiencia del investigador. El acceso al universo narrativo de Batman se realizó mediante las últimas películas del The Dark Knight, de C. Nolan, y las series animadas basadas en el Batman: The Dark Knight Return (1986) de Frank Miller. Se decidió ver como estas narrativas transmedia estaban influenciadas o se extendían a otros elementos narrativos del cómic y videojuegos y de esa forma se facilitó comenzar la exploración de esta investigación.

Hubo que seleccionar un punto de acceso y de delimitación de la observación y análisis de ciertos mundos transmedia dada la naturaleza enciclopédica y amplia del universo de Batman con material en diversos media desde su primera aparición en mayo 1939 en la historia titulada El caso del sindicato químico de la revista Detective Comics $n 27$.

Por todo ello la investigación accedió mediante las últimas películas de Batman: Batman Begins (2005), The Dark Knight (2009), y The Dark Knight Rises (2012), de C. Nolan, ver Figura 1, al universo Batman y a la narrativa transmedia que ayudó a inspirar, retroalimentar, continuar dichas narrativas a nivel de cómic, principalmente, juguetes, series, así como de interacciones de los fans, 
mediante participación en campañas, creación de machinemas, y otros. Así se observaron la relación de los diversos elementos narrativos (acciones, personajes, espacios, tiempos y valores), el tipo de interacción con los siguientes cómics: Batman Año 1 (1986), Batman: The Dark Knight Returns (1986), The Killing Joke (1988), The Man Who Falls (1989), Birth of the Demon (1992), The KnightFall (1993), Cotagion (1996), The Long Halloween (1996) y No Man's Land (1999), ver Figura 2; así como los previamente mencionados juguetes, videojuegos, campañas publicitarias, y series.

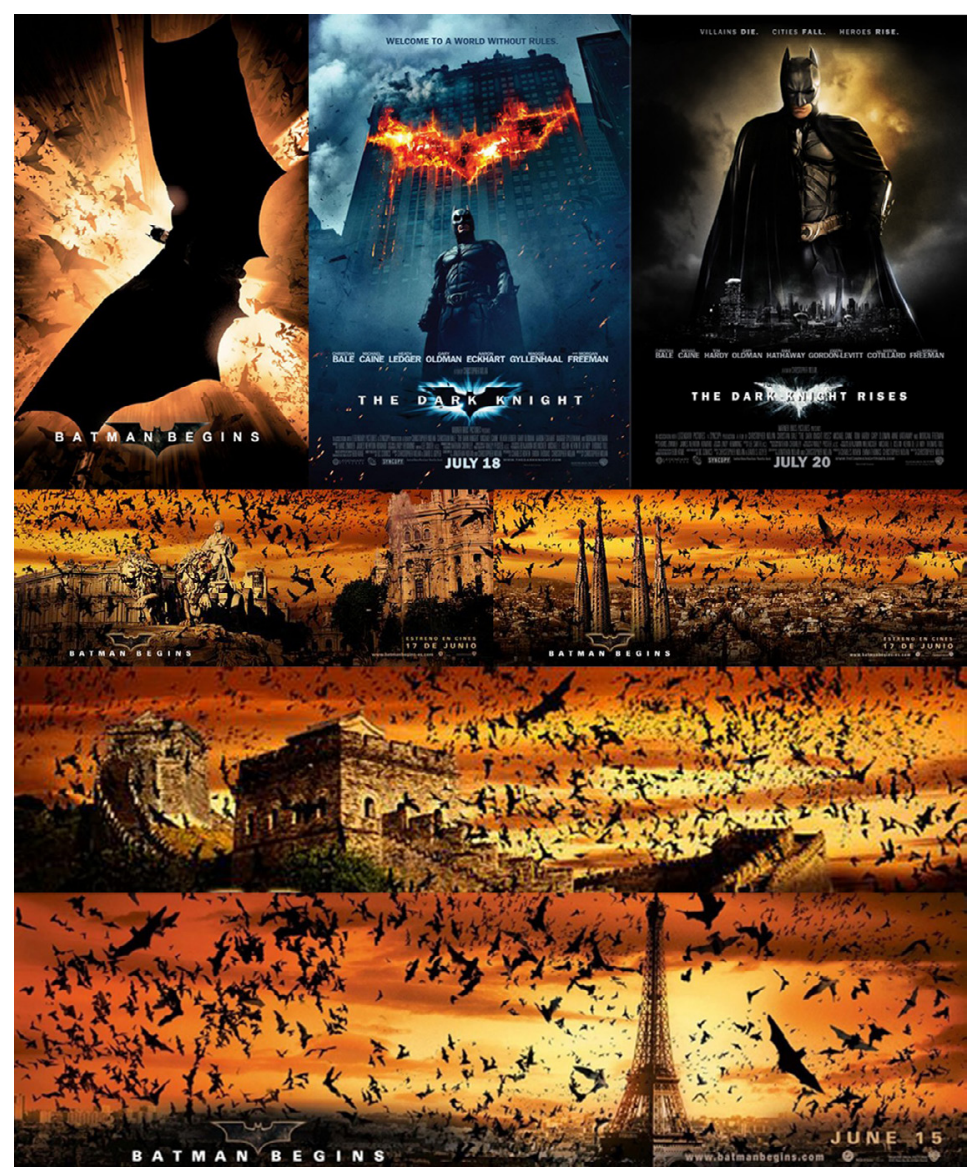

Figura 1: Carteles de la Trilogía de C. Nolan y Publicidad Transmedia que incluye los landmarks, monumentos, de las ciudades donde se iba estrenando Batman Begins. Propiedad de Warner Bros Inc. 


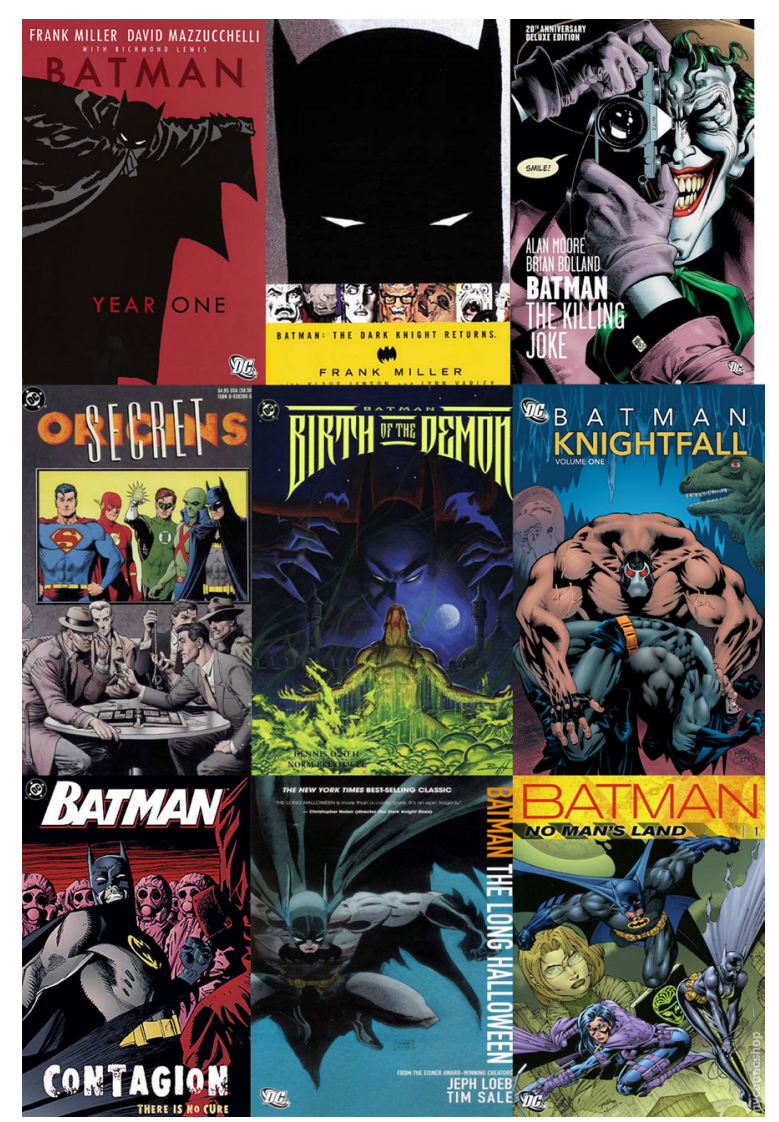

Figura 2: Portadas de los cómics analizados que generan narrativas transmedia con las películas de la trilogía de C. Nolan, webs, videojuegos, etc. Propiedad de D.C. Comics Inc

\subsection{Metodología}

\subsubsection{Características de las Narrativas Transmedia para la selección y deli- mitación del Objeto de Estudio}

Intuitivamente se considera el universo narrativo generado en torno a la figura de Batman lo suficientemente rico en sus expresiones en varios medios: cómic, televisión, series animadas, películas, videojuegos, juguetes, etc.; como para realizar un estudio enfocado en cómo se utilizaron creativamente, por diferentes autores, los elementos narrativos de Batman: acciones, personajes, espacios y tiempos, para generar, ampliar, y retroalimentar el universo transmedia de Batman. 
Sin embargo, antes de proceder al análisis y confirmar lógicamente la naturaleza transmedia de la narrativa del universo de Batman y poder analizar e identificar algunas de las dinámicas entre los diversos elementos narrativos utilizados por los diversos autores, se decidió en la presente investigación evaluar si el universo Batman cumplía con las características que Jenkins (2007) señala, Tabla 1, y Scolari confirma (2013), que debe cumplir en una narrativa transmedia.

\begin{tabular}{|l|l|}
\hline $\begin{array}{l}\text { 1) Los elementos integrales se dispersan siste- } \\
\text { máticamente a través de múltiples canales de } \\
\text { distribución. }\end{array}$ & $\begin{array}{l}\text { 6) Cada pieza narrativa del conjunto transme- } \\
\text { dia debe ser accesible en su propia forma y ha- } \\
\text { cer una contribución única al sistema narrativo } \\
\text { en su conjunto. }\end{array}$ \\
\hline $\begin{array}{l}\text { 2) La narrativa transmedia genera una sinergia } \\
\text { al difundirse entre varios medios y en diversas } \\
\text { plataformas de un mismo conglomerado mediáti- } \\
\text { co y económico. }\end{array}$ & $\begin{array}{l}\text { 7) La narrativa transmedia requiere un alto } \\
\text { nivel de coordinación entre diferentes sectores } \\
\text { mediáticos y de fuerte colaboración (o co-crea- } \\
\text { cientes y ahora con las empresas mediáticas } \\
\text { que son capaces de concebir sus propiedades } \\
\text { en términos transmedia desde el inicio. }\end{array}$ \\
\hline $\begin{array}{l}\text { 3) Las narrativas transmedia son enciclopédicas, } \\
\text { están basadas en mundos complejos que pueden } \\
\text { sostener múltiples personajes interrelacionados } \\
\text { y sus historias, no en argumentos específicos o } \\
\text { personajes individuales. }\end{array}$ & $\begin{array}{l}\text { 8) El transmedia debe contener una forma } \\
\text { estética diseñada para poder ser comprendida y } \\
\text { reconstruida por una inteligencia colectiva. }\end{array}$ \\
\hline $\begin{array}{l}\text { 4) Las diferentes narrativas transmedia en los } \\
\text { diversos medios pueden servir a diferentes } \\
\text { como extensión a funciones comunicativas y de } \\
\text { marketing }\end{array}$ & $\begin{array}{l}\text { 9) El texto transmedia provee además de } \\
\text { información sobre los roles y objetivos con los } \\
\text { que los lectores o audiencias pueden implicarse } \\
\text { desde sus vidas cotidianas. }\end{array}$ \\
\hline $\begin{array}{l}\text { 5) La práctica de la narrativa transmedia permite } \\
\text { diferentes puntos de entrada al universo narrati- } \\
\text { vo mediante diferentes segmentos de audiencias. } \\
\text { transmedia generan excesos y vacíos, insinuando } \\
\text { tramas que incentivan a los lectores a continuar o } \\
\text { especular sobre las mismas hasta tomar vida propia. }\end{array}$ \\
\hline
\end{tabular}

Tabla 1: Características que debe cumplir una narrativa transmedia.

1. En este sentido las narrativas del universo narrativo de Batman se han realizado y complementado en diversos medios creando una experiencia unificada: cómic, TV, series animadas, películas, videojuegos, juguetes, etc.

2. En este sentido Batman tiene varios ejemplos claros como, entre otros, de la campaña http://www.whysoserious.com (2008) de juego de realidad alternativa, alternate reality game, desarrollada con el lanzamiento de la película 
Elementos Narrativos que Sirven para Generar Convergencias e Inteligibilidad... | 196

The Dark Kight (2009) dirigida por Christopher Nolan, o el lanzamiento del cómic Batman Begins (2008).

3. Respecto a este requisito, la amplia bibliografía y videografía con subsecuentes referencias entre personajes, acciones, espacios y tiempos del Universo de Batman en diversas series de cómics, series televisivas, películas, videojuegos, etc, cumplen con este requisito.

4. Las extensiones narrativas como los videojuegos, los cómics basados en las películas, los juegos de rol, los juguetes, etc sirven unos a otros como extensiones narrativas para las audiencias retroalimentando la salida de la nueva aventura en un medio u otro. Por ejemplo la versión animada del Batman: The Dark Knight Returns (2012) y su enfrentamiento final entre Superman y Batman sirve para ir alimentando la expectativa de la película al tiempo que los cómics de Superman y Batman conjuntos proliferan así como las bromas de los fans. Este es el caso de nombre del viral Lego Batman: The Video Game All Cutscenes https://www.youtube.com/watch?v=0SgbVv0FE6A (2014) que se convirtió en viral con 29.259.321 de visitantes consultado en Mayo 2016. Continuando con el ejemplo de extensiones narrativas transmedia la campaña "Why so serious", www.whysoserious.com (2008) se convirtió en una campaña original de marketing viral, ver http://youtu.be/VpuC7HhCPWA. Este juego social de realidad alternativa con web y realidad aumentada, integró en una de las primeras claves a participantes fans en un contexto multitudinario como es la Feria de Comic Internacional, Comic-Con en San Diego, y que resultó en un experimento transmedia con 10 millones de participantes a través de páginas webs, juegos interactivos, teléfonos móviles, publicaciones, email, eventos reales, video y coleccionables. Esto resultó en ayudar a que el día del estreno se vendieran todas las entradas de todas las sesiones convirtiendo a la película The Dark Knight en el estreno más taquillero de todos los tiempos.

5. Algo semejante ocurrió en el ejemplo del universo narrativo de Batman donde para facilitar el acceso a diversas audiencias, las películas llevan a los cómics y de ahí a los videojuegos y estos a generar películas de machinima realizadas por fans que motivan ver las películas de imagen real y viceversa. 
6. En este sentido el transmedia debe tener la "comprensión aditiva" que señala Neil Young, diseñador de juegos, concepto que se refiere a las formas en que cada nuevo texto añade una pieza de información que sirve para revisar y reinterpretar el resto de la historia, Jenkins (2007). Por ejemplo, la narrativa de la historia del pasado de Taila con Bane es algo que se muestra de forma original en la película The Dark Knight Rises de C. Nolan (2012) que no aparece explícito en los cómics o videojuegos, proveyendo al menos de una nueva relación pasada de los personajes e incluso de una revisión de su pasado en cómics, generando lo que podría ser denominado un mundo paralelo en el Universo Batman.

7. En ese sentido directores de la talla de Cristopher Nolan, provenientes del cine independiente, al igual que reeditaron y remezclaron originalmente los elementos narrativas de su famosa película independiente Memento, saben como remezclar las narrativas para generar otras nuevas y originales, mientras mantienen y retroalimentan las historias originales en el medio que sea, como es el caso que veremos que hizo en su proceso creativo con Batman. Esto integra la práctica del concepto de la cultura de remezcla que más adelante se desarrolla.

8. Finalmente destaca como las narrativas transmedia también funcionan como activadores textuales -configurando la activación de la producción, la evaluación, y archivando la información. Los consumidores se convierten en cazadores y recolectores al moverse de un lado a otro de varias narrativas intentando aunar colectivamente una visión coherente de la información dispersa.

9. Respecto a este aspecto en el caso de los juegos y muñecos de acción Lego de Batman han motivado la creación de varios videojuegos tan populares que se han desarrollado en varias plataformas, Wii PS2, PS3, etc y en base a estas diversas versiones los fans primero y luego Warner Bros Interactive han realizado una película machinima, basada en estos videojuegos.

10. En este sentido había varios vídeos de fans en Youtube que especulaban, recopilando colectivamente información, sobre la trama de la nueva película conjunta de Superman y Batman, hasta el lanzamiento de la misma. 
En el caso de esta investigación es fundamental también tener en cuenta, para el estudio de las narrativas transmedia, el concepto de la Teoría del Remix, desarrollada por Eduardo Navas en su libro de 2012 Remix Culture, quien argumenta que "la remezcla, como forma de discurso, afecta a la cultura en formas que van más allá de la recombinación básica del material". En este sentido la teoría del remix conecta con las ideas previamente señaladas de afectar a lo que se señaló que Pierre Levy denomina como la inteligencia colectiva, así como subraya la necesidad que señalan Hayles y Kinder (2014), precursora también el concepto de database narratives aplicado también por Manovich (2001) y en su obra Soft Cinema (2005), de que existan estudios sobre las funciones de los diferentes medios y de una mirada cercana a la particular combinación específica histórica y cultural de las dinámicas de las redes transmedia. En este sentido, la obra de Steve Anderson (2011) en Technologies of History señala cómo Hal Foster se cuestiona “...¿hay una nueva dialéctica del mirar que la información electrónica nos permite?..." En este sentido el concepto de re-mezcla es una herramienta fundamental, porque se integra los conceptos de convergencia e inteligibilidad.

\subsubsection{Metodología y Modelo de Análisis Narrativo Transmedia}

El modelo que planteamos, está basado y sintetizado en Mora-Fernández (2009, $2012,2013)$, y es aquí actualizado integrando los conceptos transmedia previamente descritos, procurando de forma técnica y artística analizar los elementos utilizados en las distintas creaciones transmedia procurando identificar los elementos originales narrativos que integrados generan inmersión. Por ello este modelo, ver tabla 2, procura describir la relación entre los elementos expresivos, narrativos, emocionales y de valores que sirven para generar inmersión multisensorial, narrativa (intelectual) y emocional. Este modelo deconstructivista sirve para observar el proceso de creación y la lógica organizativa que los autores originales y empresas mediáticas realizaron en sus obras y producciones y que llegaron a transmitir a sus públicos mediante la narrativa transmedia.

Para profundizar en la lógica que hay en la combinación transmediática de los elementos narrativos (espacios, tiempos, acciones y personajes) y los valores comunicados mediante los diversos medios, y en las estrategias creativas que desarrolla una red narrativa generadora de un universo de ficción en expansión 
y que se retroalimenta, se generó el siguiente modelo de análisis comparativo transmedia del universo de Batman, tabla 2. Este modelo observa e integra las características señaladas por Jenkins, un modelo de narrativa interactiva resumido del mismo autor Mora-Fernández (2009, 2012, 2013), así como las características básicas más destacadas de cada medio que señaló Christine Weitbrecht (2013): computadora=información; televisión=vivo/series; sistemas móviles=interacción; cine=acción; videojuego=inmersión; libro=descripción. Ver Figura 3.

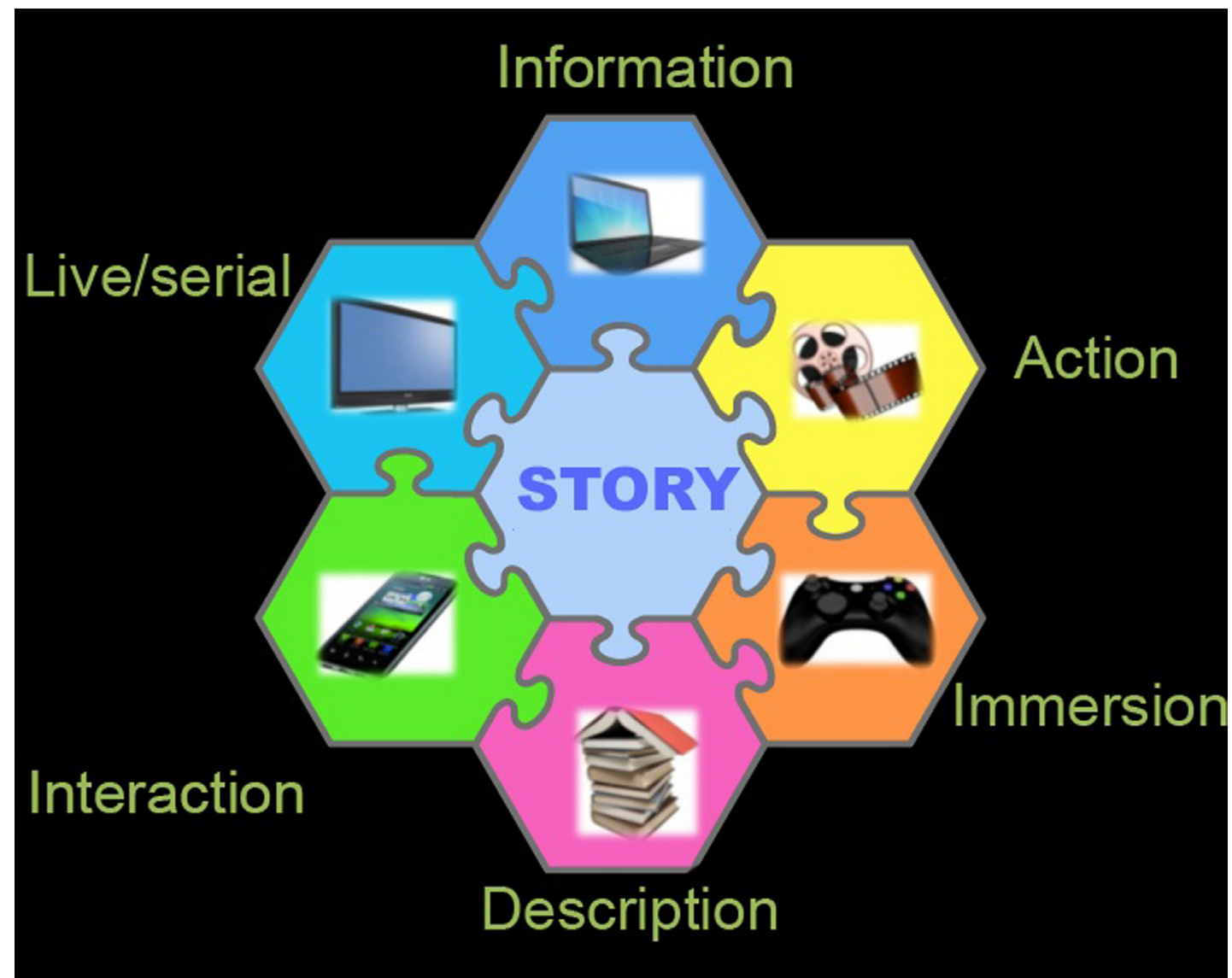

Figura 3: La historia en el centro las funciones tecnológicas de cada medio a su servicio. Diseño de C. Weitbrecht. 
1. Descripción del título de los media y de las secciones narrativas analizadas para identificar cada media analizado y poder comparar la interactividad narrativa de las secciones de los diferentes media.

2. Convergencia, inteligibilidad y lógica de la remezcla narrativa transmedia. En esta sección se describe como originalmente se obtiene la remezcla que señalaba Navas (2012), combinando las características transmedia descritas por Jenkins $(2007,2011,2013)$ en los diversos media analizados.

3. Elementos narrativos envueltos en la construcción narrativa transmedia. En esta sección se describen específicamente los denominadores comunes narrativos en cada media analizado, así como los nuevos giros y recombinaciones que presentan.

3.1. Acciones:

3.2. Personajes:

3.3. Espacios:

3.4. Tiempos:

4. Valores o desvalores transmitidos.

5. Tipo de interacción y/o medio de acceso al universo narrativo y su función. En este apartado se analizan el tipo de interacción selectiva, transformativa o constructiva.

6. Función que desempeña dentro de la narrativa transmedia y como se genera la linealidad interactiva.

Tabla 2: Modelo de Análisis de Narrativa Transmedia (origen: creación propia).

\section{Resultados y Discusión}

Dada la gran cantidad de información recopilada se describe en los apartados de resumen y discusión de los hallazgos y primeras conclusiones generales. Con fines didácticos se muestra un ejemplo de la aplicación del modelo a los diversos momentos narrativos transmedia en el Anexo 1 (D0I: ri14.v15i1.1032.s1424). Después de aplicar el modelo de análisis a más de 25 casos de narrativas transmedia que se dan dentro del universo Batman entre los media mencionados. Aquí brevemente son resumidos y mencionamos los elementos narrativos de espacios, tiempos, acciones y personajes que son gestionados a nivel cross-media para articular narrativas convergentes e inteligibles transmedia.

En la acción principal de la secuencia en la que se revela la figura que Bruce Wayne tendrá que tomar para infringir miedo a los criminales de Gotham city que combata, hay una coherencia y respeto general tanto en las series de cómics como en su transferencia narrativa transmedia a películas. Tanto en el cómic The Man Who Falls de 0`neil y Giordano, el Batman Año 1 de David Mazzuchelli y Frank Miller. DC; 
o el Batman: The Dark Knight Returns de F. Miller y en su versión animada un gran murciélago atraviesa las cristaleras con cruceras de la mansión Wayne encarando al futuro Batman. Hay matices cambiados en las acciones secundarias como que en el cómic Batman Año 1 se posa sobre el busto de su padre, o en el cómic Batman: The Dark Knight Returns está escuchando mensajes telefónicos y lo recibe con mayor madurez, pero en cualquier caso siempre está el efecto sorpresa del murciélago atravesando los cristales, rompiendo cualquier reflejo posible, y uniendo el miedo de su niñez con la memoria y el confort de ser rescatado por su padre.

Igualmente ocurre con la acción principal de la caída en la cueva de murciélagos de Bruce de niño encarando su mayor temor en las diversas secuencias narrativas transmedia entre animación, película de imagen real y cómics. Hay cambios en las acciones secundarias, en Batman Inicia, Nolan introduce el personaje de Rachel de niña, la persecución, riña por el hallazgo de la punta de una flecha o juego al escondite pero en cualquier caso cae en la profundidad de la cueva y los murciélagos se le echan encima asustándole. En el caso del cómic Batman: The Dark Knight Returns de F. Miller, Bruce persigue a un conejo y cae viendo además a un murciélago gigante, en la animación sólo aparece el rostro del mismo dando más dramatismo.

En los mismos media la muerte de los padres se produce siempre en un callejón pero en el caso de Batman Begins es a la salida forzada de la ópera, donde Bruce aún alterado asocia el teatro con la experiencia de los murciélagos al tiempo que observa personajes que serán parte de su futuro de Batman, tal como Catwoman. En Batman: The Dark Knight Returns el espacio del que salen es el cine de ver la película de El Zorro y Bruce en vez de asustado está animado peleando con enemigos imaginarios hasta que llegan al callejón del asesinato. El asesino en la película así como en Batman: The Dark Knight Returns es un criminal anónimo, en la película se aclara que el atraco se produce por necesidad y es un accidente. En cambio en la versión fílmica de Tim Burton, el asesino es un joven Joker, que de alguna forma ya disfruta con producir la muerte. En la versión de televisión de Gotham City se reproduce también la acción y espacio principales, asesinato y callejón, se respetan pero están pendientes de revelarse, esperamos al estreno, los detalles de las acciones secundarias. 
En el caso de personajes el de Catwoman y la relación de amor, odio con erotismo se desarrolla en muchos cómic de Batman pero respecto al análisis de la construcción narrativa transmedia que nos ocupa son en The Long Halloween de Loeb y Sale, y en el 503 de the The Knightfall: The Crusade, donde se retroalimenta la película The Dark Knight Rise de C. Nolan con una remezcla original. En la película Selina Kyle, Catwoman, roba y se enfrenta a Bruce Wayne el valioso collar de su madre, una acción secundaria muy significativa del romance dado que el collar recuerda por el que mataron a su madre. Pero aún es más original y extiende el universo de Batman el hecho que el enfrentamiento ante el robo sea con las identidades públicas de ambos mientras que en The Long Halloween el enfrentamiento ante el robo es con sus entidades secretas como Batman y Catwoman. Además los espacios, aun siendo perspectivas y acciones semejantes de robo de joyas en un salón lujoso y de una caja fuerte oculta, en vez de ser en casa de Bruce Wayne, como ocurre en la película, en el cómic se produce en la casa del Mafioso Falcone. Otra acción secundaria original que alimenta la narrativa transmedia es que ambos personajes en el cómic The Long Halloween bailan y besan como Bruce y Selina en la fiesta previo al robo y enfrentamiento, mientras que en la película se da ese baile posteriormente en una fiesta de beneficencia donde Selina va a robar a los ricos, y le roba el coche a Bruce después de un apasionado beso. En este sentido el tiempo de los eventos se modifica, primero baile y robo en una y al contrario en la película. Finalmente las acciones de pelea conjunta, donde uno se protege al otro, y de seducción entre Batman y Catwoman además de inspirarse en The Long Halloween tiene sus referentes en The KnightFall, serie de cómic que también inspira la lucha entre Bane y Batman de la película The Dark Knight Rises. En este último cómic no es Catwoman quien salva a Batman de Bane aunque en la película sí.

A nivel de acciones secundarias originales que remezcladas con momentos de climax de la película Batman Begins incentivan la narrativa transmedia hay que destacar: el uso del aparato de ultrasonido atrayente de murciélagos que utiliza Batman en el cómic Año 1, de David Mazzuchelli y Frank Miller, para escapar de las fuerzas especiales de la policía y no ser visto a plena luz del día. Este elemento también se utiliza en la película mencionada para poder rescatar a Rachel, amiga de la niñez de Bruce, junto a Gordon, amigo de Batman y comisario de Gotham, quien en el cómic no entra en el edificio, del veneno de pánico del Espantapájaros, enemigo de Batman 
que usa gases alucinógenos, llevándola a la Bat-Cueva e inyectándola el antídoto. La narrativa transmedia en Batman Begins, sigue también un recurso narrativo semejante de unir a antihéroes de Batman y acciones secundarias que aparecen separadas en cómics, como señalamos que C. Nolan hacía con el Joker y Two Faces en The Dark Knight. En Batman Begins Nolan integra la acción secundaria del Espantapájaros queriendo envenenar con su gas de pánico a toda la ciudad en el cómic The Shadow of the Bat- God of Fear de Grant, Blevins y George, con el complot de Ra's Al Gul, cabecilla de la Liga de las Sombras y antiguo maestro de artes marciales de Bruce, para destruir la ciudad de Gotham. Ra's Al Gul morirá en la película en el espacio de la batalla final de Bane, enemigo y alter ego de la fuerza física de Batman, en el comic, The KnightFall n666, en un tranvía, transferencia transmedia de espacios y personajes, donde Bane en realidad no muere, transferencia y paradoja de acciones secundarias, pero donde Bane sí es vencido por un nuevo Batman, acción que metafóricamente si se produce en la película The Dark Knight Rises. Además, Batman deja morir al villano Ra's Al Gul en la película Batman Begins así como el nuevo Batman hace en el cómic The KnightFall: Knightquest en el n508 con el asesino Arnold Etchison, llevando al límite sus valores de no matar al dejarlos morir. Si bien en la película Nolan justifica este hecho moral con el hecho que Bruce Wayne había salvado su vida previamente a Ra's Al Gul en medio de la montaña, acción que viene inspirada a su vez del cómic The Man Who Falls, que narra el origen de Batman. Como vemos son estas dinámicas que se producen entre los elementos narrativos de diversas series de media: cómics, películas, etc los que alimentan la curiosidad, para revisar y sumergirse en los mundos paralelos que crean los autores en el universo en expansión de Batman gracias a la narrativa transmedia.

A nivel de la transferencia del tiempo y acciones en la vida de los personajes, la acción secundaria que fortalece la amistad de Gordon y Batman, donde éste último salva a su hijo, lo que en cómic ocurre en Batman Año 1, mediante el personaje de Bruce Wayne saltando de un puente para capturar al bebé que había sido raptado por los mafiosos de Falcone; ocurre en la película de The Dark Knight cuando Harvey Dent, alias Two Faces, quien estaba en lucha contra la mafia, procura matar al hijo de Gordon, ambos de mayor edad. Estas paradojas narrativas en la película, por un lado mantienen la inteligibilidad narrativa dado que son acciones reconocibles emocionalmente por los espectadores y generadoras de empatía, y por otro invitan 
a la convergencia mediática, el explorar a quién ocurre qué y cuando en los mundos seriados del cómic u otros media. Igualmente genera una interactividad lineal al permitir la experiencia de historias completas y con sentido en cada medio además de incentivar la búsqueda y la reconstrucción de mundos paralelos en el resto de media.

El unir antagonistas es algo que ocurre en varios cómics y que llevado a un nivel transmedia genera aún más suspenso y expectativas del "aún más difícil" que incentivan a las audiencias. Por ejemplo, la transformación de Harvey Dent en Two Faces ocurre en The Long Halloween mientras que el enfrentamiento más descabellado, por acabar en risas, ocurre con el Joker en The Killing Joke de Allan Moore y en The Dark Kight Returns de Frank Miller ocurre su reencuentro mortífero, después del retiro de ambos de la actividad. Christopher Nolan integra en la película a ambos personajes, Two Faces y el Joker, jugando con las estructuras narrativas donde un coprotagonista, Harvey Dent, se convierte en co-antagonista, Two Faces, generando más tensión para Batman y el espectador en un solo media. Igualmente la acción secundaria y resolución se modifica, donde en el cómic Batman: The Dark Knight Returns muere el Joker, es en la película Harvey Dent, Two Faces, quien fallece. Además se importa del cómic The Killing Joke a la película la conversación del Joker y Batman sobre como son alter egos, seres complementarios, donde no muere el Joker, aunque paradójicamente sí el actor por consecuencias de la adicción activa, consiguiendo además un premio 0scar póstumo. De esta forma se retroalimentan las narrativas transmedia y el director de la película procura integrar las tramas, subtramas, personajes y acciones que más éxito y culto han tenido por las audiencias a nivel de cómics, como son The Knightfall $(1983,1984)$, The Killing Joke (1988), No Man's Land (1999-2000), Batman: The Dark Knight Returns (1986), creando algo nuevo de tal remezcla.

Al remezclar acciones principales de cómics del Batman que han tenido éxito de público, tales como en The Knight Fall número 666 cuando el nuevo Batman derrota a Bane, antagonista que previamente había dejado paralítico a Batman, con otros personajes, en una batalla en un tranvía que descarrila, que se transfiere a Ra's al Ghul, en el caso del final de la película de Batman Begins(2005). Con estas remezclas narrativas la inmersión comunicativa de los espectadores se incrementa, al tiempo que retroalimenta y revalora los cómics originales, dado que, como en el caso del investigador, llama la atención a los fans el buscar en que cómics de Batman está basada la acción principal y las secundarias. 
Si además se integran varias acciones secundarias de momentos épicos del Batman, por ejemplo cuando Bane en la serie de cómics de The Knight Fall busca generar el caos en Gotham City, haciendo escapar mediante explosiones a todos los criminales del Arkham Asylum. 0 cuando del Scarecrow que amenaza a toda la ciudad, en el cómic The God of Fear (1993), que dispersará su gas veneno alucinógeno incentivador de los miedos y pánicos más profundos de quienes lo inhalen, resulta el clímax final de la película Batman Begins, donde en paralelo ocurren las acciones secundarias descritas mientras Ra's al Ghul pasea en tranvía por toda la ciudad haciendo evaporar el agua contaminada de las alcantarillas y dirigiéndose hacia el distribuidor de agua central de Gotham infectando a toda la ciudad, argumento principal también del cómic Contagion (1996).

En síntesis, las acciones secundarias que en paralelo suman suspense para el desenlace de la acción principal, re-mezclando personajes y acciones en espacios reconocibles en narrativas previas, sirve para incentivar la inmersión psicológica y emocional comunicativa, reconexión de espacios, tiempos, acciones y personajes, así como incrementa la adrenalina en la experiencia presente, al tiempo que incentiva la interacción transmedia de las audiencias, quienes buscarán investigar en otro medio sobre los orígenes y futuros de los personajes y acciones de la película.

Por último destacar la capacidad de C. Nolan y su equipo de generar narrativas transmedia dado que son capaces de jugar con los mayores sutiles detalles tales como: 1) Recoge la frase final que Gilda, la esposa de Harvey Dent, quien dice al final del cómic The Long Halloween, "I believe in Harvey Dent" para utilizarla en la campaña publicitaria www.whysoserious.com, campaña de atracción del Joker de miembros a su gang, y I believe in Harvey Dent, web de promoción política de Harvey para la ciudad de Gotham City, antes del lanzamiento de la película The Dark Knight. 2) Frase que Gilda dice después que Harvey Dent se entregue a Batman y Gordon en el cómic, manteniendo la integridad en un espacio y mise-en-scène semejante al que ocurre en la película The Dark Knight, salvo que en esta pierde la integridad al intentar matar al hijo de Gordon, y después que Harvey se haya convertido en Two Faces por un ácido lanzado en el juicio por Marony, enviado por Falcony, The Roman, a quien mata en el cómic. 3) Marony es el enjuiciado en la película y durante el juicio Harvey en vez rociarle de ácido, como en el cómic, le intentan disparar con una pistola defectuosa. De estas formas y re-mezclando los 
Elementos Narrativos que Sirven para Generar Convergencias e Inteligibilidad... | 206

elementos narrativos señalados Nolan crea una narrativa transmedia que origina mundos paralelos o alternativos entre los cómics mencionados, la película, las narrativas emergentes de los fans así como con la campaña viral de marketing.

\section{Conclusiones Finales}

Una de las primeras conclusiones recogidas es que la preexistencia de narrativas seriales y bases de datos amplias en un media que incluya elementos narrativos modulares de ciertos personajes reconocibles por su apariencia, capacidades o personalidad y que realizan acciones familiares y/o nuevas en espacios y tiempos originales, no realizados antes, sirven como materia prima, mundo narrativo potencial, para generar nuevas narrativas transmedia mediante la aplicación del concepto de remix culture. La capacidad de re-mezclar original y sutilmente en nuevas estructuras los mismos elementos narrativos desde diversas perspectivas generan diversas lecturas y mundos paralelos, consecutivos y complementarios que sirven para generar narrativas que extienden ese mundo mediático a un universo transmedia.

Esto se debe, como vimos previamente, a que la película rescata e inspira varios elementos narrativos de dichos cómics re-mezclando sus acciones, personajes, tiempos y espacios narrativos de una forma original, siguiendo la rica tradición del cómic seriado de Batman, y dando mayor profundidad en los media; cine, videojuegos, webs, etc, y dando otros ángulos a los diversos personajes, acciones y situaciones del universo Batman. La ciudad Gotham City, con una nueva serie televisiva del canal Fox series, parte del consorcio de empresas de Warner Bros y D.C. Los co-protagonistas en las historias: Gordon, Robin, Catwoman, Harvey Dent (luego Dos Caras), Alfred, etc, sus antagonistas, Joker, Dos Caras (Two Faces), El Espantapájaros (Scarecrow), etc; junto con el tratamiento del espacio y tiempo, son introducidos con transferencias de espacios con los personajes, continuidad temporal transmedia y mundos paralelos, mediante el cambio en matices de los orígenes, motivaciones o características de los personajes al presentar otros backgrounds de los personajes y de la ciudad, que muestran contextos espacio temporales desconocidos, previamente a donde se formaron en los cómics los caracteres, las cualidades, o las características físicas o psicológicas de los personajes. La consolidación en el cine y en otros medios del universo Batman han apoyado y retroalimentado la incursión en el desarrollo de videojuegos con narrativas transmedia de fans, utilizando 
las películas machinima, basadas en videojuegos como Batman Arkham Archives (2009) o Injustice Gods Among Us (2013). El concepto de remezcla sirve para describir cómo se consigue generar narrativas transmedia y la linealidad interactiva generada en un mundo narrativo. La extensión narrativa se convierte así en una mezcla original que genera algo emergente en la narrativa del nuevo medio, que no existía en los anteriores, al añadir material innovador a la construcción del universo narrativo transmedia.

En resumen, que las narrativas transmedia tengan una mezcla nueva de elementos narrativos reconocibles, hagan uso de la cultura remix, genera inmersión en los mundos creados. Como ejemplo humorístico, y en honor a la fuerte influencia en toda Iberoamérica de los personajes de "Chespirito", el Chavo del 8, el Chapulín Colorado, etc, y artista recientemente difunto en el momento de la escritura de este artículo, valga poner como ejemplo una serie de cómic de Batman y el Chapulín Colorado, ver Figura 4. En ella el Chapulín apoya a Batman en la lucha contra el crimen en Gotham pero al cruzarse con Catwoman ella se queda prendado de Chapulín, dejando a un lado su pasión por Batman, y surgiendo de la apasionada relación entre Chapulín y Catwoman un nuevo superhéroe, Chapucat, ver Figura 5, cuya existencia inspirará a Batman a buscar aún más venganza dado que es el producto de la que fue su amante Catwoman y su nuevo compañero Chapulín Colorado, con el que no contaba con su astucia.

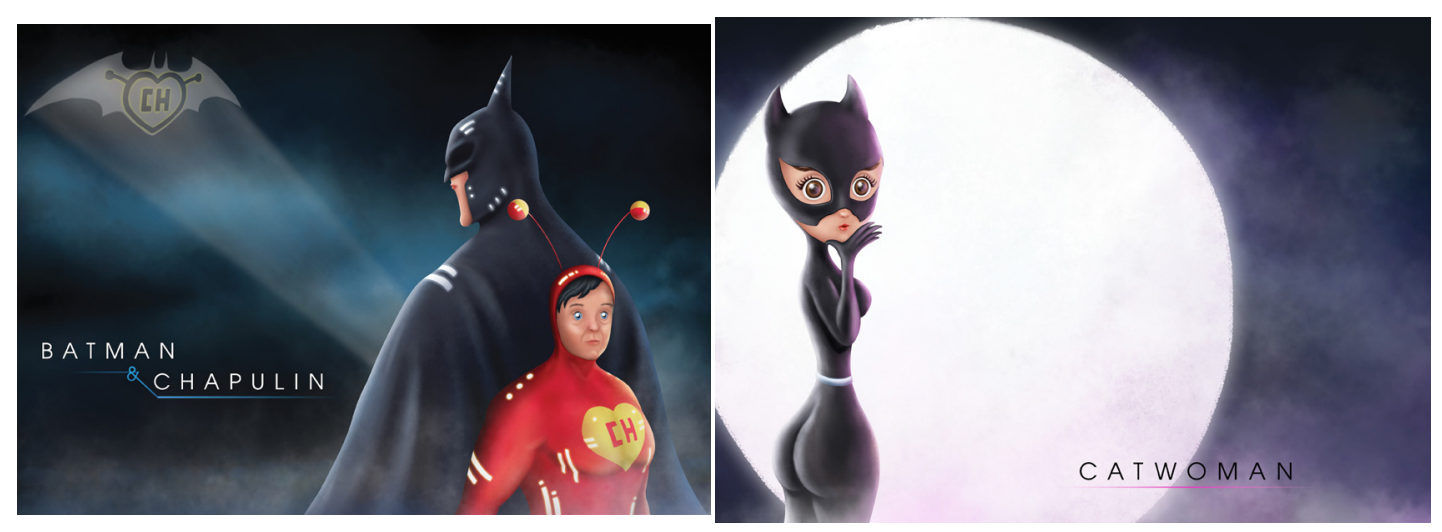

Figura 4: Imágenes de una tentativo cómic iberoamericano Batman Vs Chapulín Colorado. (Origen: Concepto Jorge Mora . Ilustración Javier Carchipulla) 

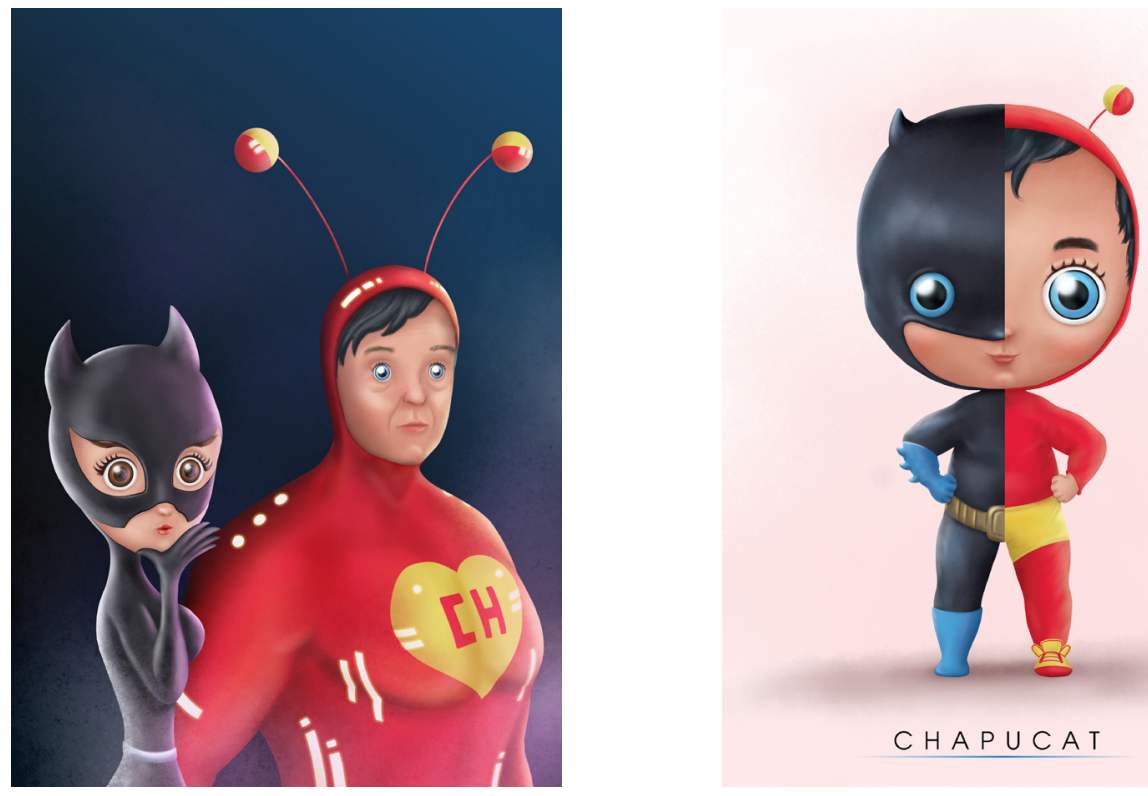

Figura 5: Imágenes del una tentativo cómic iberoamericano Batman Vs Chapulín Colorado. Donde el Chapulín Colorado utilizando su astucia conquista a Catwoman dando lugar a un nuevo superhéroe ChapuCat. (Origen: Concepto Jorge Mora. Ilustración Javier Carchipulla)

\section{Referencias}

Anderson, Steve. (2011). Technologies of History. Lebanon. Dartmouth College Press. Bruni, E., Baceviciute, S. (2013). Narrative Intelligentibility and Closure in Interactive Systems. Heidelberg. En Koenitz, H. et al. (eds.) ICIDS 2013. Heidelberg. LNCS, vol. 8230, pp.13-15, 18, 22. Springer.

Beatty, et all. (2008). Batman Begins. Barcelona. España: Planeta DeaGoscini. Boon, Ed y Grinsfelder, Dean (2013). Injustice. Gods Among Us. Los Angeles. Warner Bros Interactive Enterntainment.

Dixon, C; Nolan, G. y Barreto, E. (1993). Vengeance of Bane en The KnightFall series. New York. D.C. Comics Inc.

Grant, A. y Dixon, C. (1996). Batman Contagion. New York. D.C. Comics Inc. Hill, Sefton y Dini, Paul. (2009). Batman Arkham Archives. Los Angeles. Warner Bros Interactive Enterntainment. 


\section{MONOGRÁFICO}

Hurup Bevense, S., Schoenau-Fog, H. (2013). Conceptualizing Productive Interactivity in Emergent Narratives. Heidelberg. En Koenitz, H. et al. (eds.) ICIDS 2013. Heidelberg. Springer. LNCS, vol. 8230, pp. 61, 62.

Jenkins, Henry (2007). USC. Los Ángeles. Recuperado de http://henryjenkins. org/2007/03/transmedia_storytelling_101.html

Jenkins, Henry (2011). USC. Los Ángeles. Recuperado de http://henryjenkins. org/2011/08/defining_transmedia_further_re.html

Jenkins, Henry (2013). USC. Los Ángeles. Recuperado de http://henryjenkins. org/2013/02/what-transmedia-producers-need-to-know-about-comics-aninterview-with-tyler-weaver-part-two.html

Jenkins, Henry. (2006). Convergence Culture. New York: New York University Press. Loeb, J. y Sale, T. (1996). The Long Halloween. New York. D.C. Comics Inc.

Kinder, Marsha et al. (2014). Transmedia Frictions: The Digital, the Arts, and the Humanities. Oakland: University of California Press.

Mateas, M., Murray, J. (2004) A Preliminary Poetics for Interactive Drama and Games, and From Game-Story to Cyberdrama. In Wardrip-Fruin N., Harrigan P. (eds.) First Person: New Media as Story, Performance and Game. Cambridge:The MIT Press, Manovich, Lev (2005). Soft Cinema. Cambridge: M.I.T. Press..

Manovich, Lev (2001). The Language of New Media. Cambridge: M.I.T. Press.. Mazzucchelli, D. y Miller, F. (1986). Batman Year One. New York: D.C. Comics Inc. Moore, A. y Bolland, B. (1988). The Killing Joke. New York: D.C. Comics Inc. Mora, Jorge. (2013). Artecnología en cine interactivo: algunas categorías, interfaces, estructuras narrativas, emociones e investigaciones. En ArTecnologia. Arte, Tecnologia e linguagens Midiáticas. Rio de Janeiro: Editorial. Buqui.

Mora-Fernandez, Jorge I. (2009). La interfaz hipermedia: el paradigma de la comunicación interactiva. Modelos para implementar la inmersión juvenil en multimedia interactivos culturales. (Videojuegos, cine, realidad aumentada, museos y web). Madrid: Fundación Autor,

Mora-Fernandez, Jorge I.(2012). Medios interactivos y cultura digital: Alfabetízación hipermedía en Perú y Bolivia. [The analysis of interactive media and digital culture: Hypermedia literacy in Peru and Bolivia]. Revista Comunicar, 20(39), p.139-149. https://doi.org/10.3916/C39-2012-03-04

Moreno Sánchez, Isidro (2002). Musas y Nuevas Tecnologías: El relato hipermedia. Barcelona: Paidós Comunicación. 
Murray, J. (2012): Inventing The Medium. Principles of Interaction, Design as a Cultural Practice. Cambridge: The MIT Press.

Nolan, Christopher. (2005). Batman Begins. USA. Warner Bros Inc.

Nolan, Christopher. (2009). The Dark Knight. USA. Warner Bros Inc.

Nolan, Christopher. (2012). The Dark Knight Rises. USA. Warner Bros Inc.

Oliva, Jay. (2012). Batman: The Dark Knight Returns. USA. DC Universe Animated Original Movies.

O'neil, D. y Giordano, D. (1989). The Man Who Falls in Secrets Origins. New York: DC Comics Inc.

O'neil, D. y Breyfogle, N. (1992). Birth of the Demon. New York: DC Comics Inc.

O'neil, D; Jordan, B. Y Gorfinkel (1999). No Man's Land. New York: DC Comics Inc.

Ryan, Marie-Laure. Narrative as Virtual Reality. Maryland: The John Hopkins University Press, 2001.

Scolari, Carlos (2013). Narrativas transmedia: cuando todos los medios cuentan. Barcelona: Deusto.

Truesdale, J., et al. (2013). Suitability of Modelling Context for Use within Emergent Narrative. Heidelberg. En Koenitz, H. et al. (eds.) ICIDS 2013. LNCS, vol. 8230, p. 65. Springer.

Venegas, Cristina (2010). Digital Dilemmas, The State, the Individual, and Digital Media in Cuba. New Brunswick: Rutgers University Press.

Warner Bros Inc. (2008) Los Ángeles. Recuperado de http://www.whysoserious. com, www.youtube.com/watch?v=pYpaL5CmDTM

Weaver, Tyler (2012). Comics for Film, Games, and Animation: Using Comics to Construct Your Transmedia Storyworld. Burlington: Focal Press.

\section{Agradecimientos}

Programa Prometeo-SENESCYT, Secretaria Nacional de Educación Superior, Innovación, Ciencia y Tecnología y a la DIUC, Dirección de Investigación de la Universidad de Cuenca, Ecuador, y Arthur C. Clarke Center for Human Imagination, University of California San Diego que hicieron posible esta investigación. 